Received, 1 November 2018 Accepted, 5 December 2018 Link to DOI: 10.25220/WNJ.V02.i2.0004

Journal Website: www.worldnutrijournal.org

\title{
Nutritional Status Influences High-Molecular Weight (HMW) Adiponectin Levels in Breast Cancer Patients: Comparison with Healthy Controls
}

Ainaa Almardhiyah Abd Rashid ${ }^{1}$, Zunura'in Zahali ${ }^{2}$, Venkata Murali Krishna Bhavaraju ${ }^{3}$, Gan Siew $\mathrm{Hua}^{4}$, Sarimah Abdullah ${ }^{5}$, Sharifah Zahhura Syed Abdullah ${ }^{6}$, Hamid Jan Jan Mohamed ${ }^{7}$

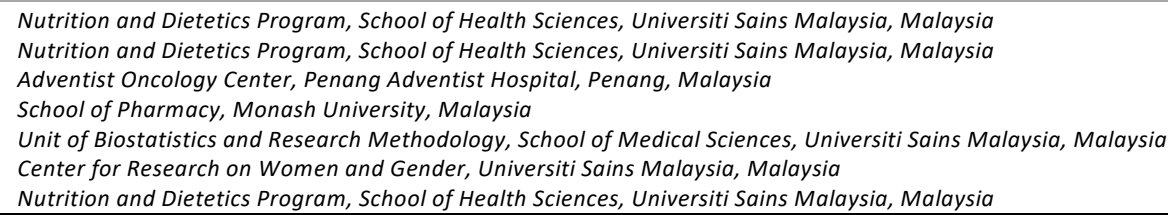

Nutrition and Dietetics Program, School of Health Sciences, Universiti Sains Malaysia, Malaysia Nutrition and Dietetics Program, School of Health Sciences, Universiti Sains Malaysia, Malaysia Adventist Oncology Center, Penang Adventist Hospital, Penang, Malaysia

School of Pharmacy, Monash University, Malaysia

Unit of Biostatistics and Research Methodology, School of Medical Sciences, Universiti Sains Malaysia, Malaysia

Center for Research on Women and Gender, Universiti Sains Malaysia, Malaysia

Nutrition and Dietetics Program, School of Health Sciences, Universiti Sains Malaysia, Malaysia

\begin{abstract}
Introduction Breast cancer is the leading killer of women in Malaysia. Nutritional status and adiponectin are modifiable risk factors for breast cancer occurrence which can be efficiently targeted. The purpose of this study was to determine the relationship between nutritional status and high molecular weight (HMW) adiponectin levels among breast cancer patients as compared to controls.

Methods This was a case- control study, conducted in Hospital Universiti Sains Malaysia and Universiti Sains Malaysia campus. Newly diagnosed breast cancer cases $(n=55)$ were assigned as cases while healthy controls $(n=58)$ were staff members of HUSM and USM campus. Sociodemographic and reproductive data were obtained with a standard questionnaire while the dietary data was obtained from a validated diet history questionnaire. Anthropometric assessments [weight, height, hip, waist circumference (WC) and body fat composition] were measured while overnight fasting venous blood samples were analysed for lipid profiles, glucose, insulin, high sensitivity C-reactive protein and HMW adiponectin.

Results A significant linear negative relationship exists between WC and HMW adiponectin $(\beta=-$ 0.05; $p=0.005$ ) among breast cancer cases. Additionally, HDL cholesterol was positively associated with HMW adiponectin $(\beta=1.83 ; p=0.010)$ among the cases. BMI was negatively associated with HMW adiponectin ( $\beta=-0.02 ; p=0.001)$ among healthy controls.

Conclusion Our findings suggest that WC, BMI and HDL cholesterol had significant relationship with HMW adiponectin. Low levels of HMW adiponectin, low WC and high HDL levels may be protective against breast cancer.
\end{abstract}

Keywords nutritional status, high-molecular weight adiponectin, waist circumference, body mass index, high density lipoprotein cholesterol, breast cancer

\section{Introduction}

Breast cancer is the most common cancer among Malaysian women, where its rates in Malaysia are

\section{Corresponding author:}

Name: Hamid Jan Jan Mohamed

Address: Nutrition and Dietetics Program, School of Health Sciences, Universiti Sains Malaysia, Kubang Kerian 16150, Kelantan, Malaysia

Phone numbers: +6097677618

Facsimile numbers: +6097677515

E-mail address: hamidjan@usm.my higher than that reported in Southeast Asian countries. ${ }^{1}$ One of the risk factos for breast cancer is obesity $^{2}$ where the prevalence of overweight, obesity and abdominal obesity among Malaysian women have been reported to be $28.3 \%, 20.6 \%$ and 
$60.2 \%$, respectively. In addition, the National Health and Morbidity Survey (NHMS) 2015 reported that there was an increasing trend in the adiposity prevalence among Malaysian women in 2015 compared with $2011 .^{3}$

Nutritional status is an essential predictor of clinical outcome such as malnutrition. Impaired nutritional status have been linked with inadequate food intake, unsustained hunger and metabolic inefficiency. ${ }^{4}$ Several studies modulated nutritional status as the assessment of anthropometry and body composition such as body mass index and body fat distribution. ${ }^{5}$ In contrast, nutritional status also has been defined in the scope of dietary intake by considering food intakes and utilisation of nutrients were affecting the consumer's health condition. ${ }^{6}$

Two main modifiable risk factors in prevention of cancer are body weight and dietary intake. ${ }^{7}$ However, the American Cancer Society provided new nutritional guidelines for prevention of cancer by grouping the recommendations into various categories of weight management, physical activity and dietary intake. ${ }^{8}$ This recommendation is useful as nutritional education in promoting good health and optimum nutritional status among public. Moreover, in an effort to increase patient's quality of life, nutritional status is an important concern. For example, the Subjective Global Assessment (SGA) form has been utilized to screen patients with malnutrition in HUSM. This nutritional assessment tool may guide the incorporation of nutritional intervention in overcoming disease complications. ${ }^{9}$

Previously, adipose tissue was thought to function only for storing fat for energy. However, recently it was recognized that adipose tissue is an endocrine organ that releases large amounts of biochemical modulators, including adipokines. ${ }^{10}$ Among these adipokines, adiponectin which abundantly circulates in the plasma at high concentrations ( 0.5 to $30.0 \mu \mathrm{g} / \mathrm{ml}$ ) and accounts for up to $0.01 \%$ of total plasma proteins ${ }^{11}$ are thought to play a major role in breast cancer development. Adiponectin exists in the plasma as trimer, hexamer or high molecular weight (HMW) adiponectin isoforms. Among these, the HMW isoform is the most biologically active form and is strongly associated with insulin resistance, metabolic syndrome, and cardiovascular disease. ${ }^{12}$

Adiponectin is considered to be a protective hormone because it plays a major role in the regulation of glucose due to its potent insulin- sensitizing activity which affect the uptake of glucose in the muscle. Furthermore, it is involved in lipid homeostasis, and in the pathophysiology of atherosclerosis due to its anti-inflammatory activity. ${ }^{13}$ Numerous studies have shown that adiponectin has an inhibitory effect on the proliferation of various cell types, including aortic smooth muscle, endothelial tissue and several types of cancer cells. ${ }^{14}$ It has been hypothesized that adiponectin act directly on breast cancer cells by inhibiting proliferation and angiogenesis or by stimulating apoptosis. ${ }^{15}$ Serum adiponectin is therefore a potential therapeutic target for breast cancer treatment or protection. ${ }^{16}$

Although adiposity is a well-established health problem related to breast cancer, the data on the association between HMW adiponectin and adiposity obtained from various epidemiological studies has remained elusive in Asian countries, particularly Malaysia. Therefore, the aim of this study was to investigate the relationship between nutritional status and HMW adiponectin levels among breast cancer patients as compared to healthy controls. It is hoped that the data will provide essential information for health professionals planning public health programs for breast cancer prevention in Malaysia with respect to weight and reproductive health management.

\section{Methods}

\section{Setting and subjects}

This is a case-control study conducted in Kelantan, Malaysia, approved by the Human Research and Ethical Committee of USM. The cases include newly diagnosed women with histologically confirmed malignant breast cancer (stages I to IV) who had not yet undergone any therapies (except for analgesics and/or surgery) while the controls comprised of healthy volunteers with no known history of breast cancer, any other medical illness or medication use. The inclusion criteria for both cases and controls were women aged 20 to 59 years old who were neither pregnant nor lactating during the study periods. Both cases and controls were recruited using a convenience sampling method while the controls were selected to match the cases for age \pm 10 years.

\section{Measurements}


Written informed consents were obtained and the respondents underwent face-to-face interviews using a set of questionnaires including validated diet history questionnaire (DHQ). ${ }^{17}$ The respondents were measured for height using a portable stadiometer, weight and fat composition using a body composition analyzer (TANITA SC-330, Japan), waist circumference (WC) and hip circumference using a non-extendible tape. BMI was calculated by dividing the weight $(\mathrm{kg})$ by the square of the height $(\mathrm{m})$. Fasting blood samples were collected for biochemical test. Serum HMW adiponectin concentrations were measured using a sandwich ELISA kit.

Statistical analyses were performed using SPSS for Windows, version 22.0. Categorical data were presented as frequency (percentage), while chisquared or Fisher's exact tests were used to determine the association between any categorical variables. Independent samples t-test was used to compare means and multiple linear regression analyses were used to investigate the associations between HMW adiponectin levels and nutritional status. A p value of less than 0.05 was considered as statistically significant.

\section{Results}

A total of 55 newly diagnosed breast cancer cases and 58 healthy controls were recruited (Table 1). The mean (SD) age for cases and controls were 46.84 (7.87) years and 40.79 (9.78) years respectively. Education level of the cases mostly from primary or secondary school when compared to controls most of whom graduated from the university. The majority of the respondents were premenopausal women, practiced family planning, breastfed their babies, with no first degree family history of breast cancer. A higher percentage of cases $(58.2 \%)$ were exposed to second-hand smoke as compared to controls $(29.3 \%)$.

Multiple linear regression analysis revealed that there was a significant linear negative relationship between WC and HMW adiponectin ( $p$ $=0.005$ ) where a $10 \mathrm{~cm}$ increase in WC lowers HMW adiponectin levels by $0.5 \mu \mathrm{g} / \mathrm{ml}(95 \% \mathrm{CI}$ : $0.8,-0.2 \mu \mathrm{g} / \mathrm{ml}$ ) (Table 2). In addition, HDL cholesterol was positively associated with HMW adiponectin $(p=0.006)$. Furthermore, a $1 \mathrm{mmol} / \mathrm{L}$ increase in HDL cholesterol increases HMW adiponectin levels by $1.83 \mu \mathrm{g} / \mathrm{ml}(95 \% \mathrm{CI}: 0.47$, $3.02 \mu \mathrm{g} / \mathrm{ml})$.

Table 3 shows the associations of nutritional status with HMW adiponectin among healthy controls. Multiple linear regression analysis revealed that there was a significant $(p=0.001)$ linear negative relationship between BMI and HMW adiponectin where a $1 \mathrm{~kg} / \mathrm{m} 2$ increase in BMI lowers HMW adiponectin levels by $0.20 \mu \mathrm{g} / \mathrm{ml}(95 \% \mathrm{CI}$ : $0.32,-0.08 \mu \mathrm{g} / \mathrm{ml})$.

\section{Discussion}

Mean age at breast cancer diagnosis showed that mean age breast cancer cases were significantly older than healthy controls. This result is in a good agreement with the previous results reported by Fuhrman et al., who also had frequency matching case control by birth year in 5- year strata in United States. ${ }^{18}$ Age matched in this study was quite wide $( \pm 10$ years) because of the difficulty faced in matching the older cases with older controls free from diseases as older women are synonym with the disease. However, one study from Vietnam found no significant difference in age between case and control groups matched on a single year of age. ${ }^{19}$

According to a study conducted in Malaysia on breast cancer awareness, they concluded that education level emerged to contribute to health behavior and knowledge level, based on an outcome of women had higher education level were significantly more aware of breast cancer. ${ }^{20}$ In this present study, breast cancer cases mostly from primary and secondary school compared to healthy controls most of whom graduated from university. Poor education had accounted for late stage at presentation of breast cancer. ${ }^{21}$ A qualitative study was conducted by exploring the decision-making experiences of breast cancer women and discovered four phases in the decision-making process (discovery, confirmatory, deliberation and decision). Their knowledge, understanding and experiences affect the final decision for treatment. ${ }^{22}$

Majority of the breast cancer cases were premenopausal women and this may be explained 
Table 1 Baseline characteristics of the respondents ${ }^{\mathrm{a}}$

\begin{tabular}{|c|c|c|c|}
\hline Variables & $\begin{array}{l}\text { Cases } \\
(\mathrm{n}=55)\end{array}$ & $\begin{array}{l}\text { Controls } \\
(\mathrm{n}=58)\end{array}$ & p value ${ }^{\mathrm{c}}$ \\
\hline Age (years) ${ }^{b}$ & $46.84(7.87)$ & $40.79(9.78)$ & 0.001 \\
\hline \multicolumn{4}{|l|}{ Education level } \\
\hline $\begin{array}{l}\text { Primary/secondary } \\
\text { school }\end{array}$ & $35(63.6)$ & $21(36.2)$ & \multirow[t]{2}{*}{0.004} \\
\hline University & $20(36.4)$ & $37(63.8)$ & \\
\hline \multicolumn{4}{|l|}{ Exposure to second-hand smoke } \\
\hline Yes & $32(58.2)$ & $17(29.3)$ & \multirow[t]{2}{*}{0.002} \\
\hline No & $23(41.8)$ & $41(70.7)$ & \\
\hline \multicolumn{4}{|l|}{ Monthly household income (RM) } \\
\hline$<\mathrm{RM} 2,300$ & $31(57.4)$ & $4(7.3)$ & $<0.001$ \\
\hline RM 2,300-5,599 & $13(24.1)$ & $34(61.8)$ & \multirow[t]{2}{*}{0.403} \\
\hline$>$ RM 5,600 & $10(18.5)$ & $17(30.9)$ & \\
\hline \multicolumn{4}{|l|}{ Family planning } \\
\hline Yes & $28(50.9)$ & $37(63.8)$ & \multirow{2}{*}{0.167} \\
\hline No & $27(49.1)$ & $21(36.2)$ & \\
\hline Age during first pregnancy,years ${ }^{b}$ & $25.75(5.23)$ & $25.34(2.66)$ & 0.631 \\
\hline Parity ${ }^{b}$ & $3.61(2.03)$ & $3.25(1.97)$ & 0.335 \\
\hline \multicolumn{4}{|l|}{ Breastfeeding } \\
\hline Yes & $50(90.9)$ & $48(82.8)$ & \multirow[b]{2}{*}{0.209} \\
\hline No & $5(9.1)$ & $10(17.2)$ & \\
\hline \multicolumn{4}{|l|}{ Menopausal status } \\
\hline Premenopause & $42(76.4)$ & $51(87.9)$ & \\
\hline Postmenopause & $13(23.6)$ & $7(12.1)$ & 0.113 \\
\hline \multicolumn{4}{|c|}{ First degree family history with breast cancer } \\
\hline Yes & $6(10.9)$ & $2(3.4)$ & \multirow[t]{2}{*}{0.142} \\
\hline None & $49(89.1)$ & $56(96.6)$ & \\
\hline \multicolumn{4}{|c|}{$\begin{array}{l}\text { Note. } \mathrm{SD}=\text { Standard deviation; } \mathrm{OR}=\text { Odds ratio; } \mathrm{CI}=\text { Confidence interval } \\
\text { a Data are presented as frequency (percentage), unless otherwise indicated } \\
{ }^{\mathrm{b}} \text { Data are presented as mean (SD) } \\
{ }^{\mathrm{c}} \mathrm{p} \text { value based on Independent } \mathrm{t}-\text { test } \\
\text { dBased on the cut-off of the } 10^{\text {th }} \text { Malaysia Plan } \\
\text { e Sample size was not } \mathrm{n}=113 \text { due to missing values }\end{array}$} \\
\hline
\end{tabular}

through breast cancer is typically more aggressive in women under 40 years of age than in older women. ${ }^{23}$ This is ordinarily applied to the fact that tumors in premenopausal women bear a higher percentage of biologically negative cellular or histological features which led to a worse prognosis. ${ }^{24}$

In this study, exposure to secondhand smoke was significantly associated with breast cancer. This finding was consistent with recent study on nonsmoking breast cancer women with lifetime exposure to passive smoking. Exposure to secondhand smoke had 1.27 (95\% CI: 0.97, 1.66) (less than 20 years) and 2.64 (95\% CI: 1.87, 3.74) (more than 20 years) times increase risk of breast cancer than unexposed women. Besides that, Caucasian women who experienced second-hand smoke both at work and home had $2.80(95 \% \mathrm{CI}: 1.84,4.25)$ times higher risk of breast cancer compared with women who were never exposed to smoke. ${ }^{25}$

To our knowledge, our study is the first to establish that WC and HDL cholesterol levels are associated with HMW adiponectin among breast cancer cases. In addition, BMI is also associated with HMW adiponectin among healthy controls. Our study successfully determined the association between nutritional status and HMW adiponectin among breast cancer cases and healthy controls.

WC was negatively associated with HMW adiponectin among breast cancer cases which was consistent with another study among obese and nonobese Caucasians indicating that WC is inversely correlated with HMW adiponectin level regardless 
Table 2 Associations of nutritional status with HMW adiponectin among breast cancer cases

\begin{tabular}{|c|c|c|c|c|}
\hline \multirow[t]{2}{*}{ Variables } & \multicolumn{2}{|l|}{ Simple linear regression } & \multicolumn{2}{|c|}{ Multiple linear regression } \\
\hline & $\mathrm{b}^{\mathrm{a}}(95 \% \mathrm{CI})$ & $\mathrm{p}$ value & $\begin{array}{l}\text { Adjusted } b^{b} \\
(95 \% \mathrm{CI})\end{array}$ & $\mathrm{p}$ value \\
\hline Weight (kg) & $-0.05(-0.08,-0.02)$ & 0.001 & & \\
\hline Height (cm) & $-0.01(-0.09,0.07)$ & 0.870 & & \\
\hline $\operatorname{BMI}\left(\mathrm{kg} / \mathrm{m}^{2}\right)$ & $-0.13(-0.21,-0.06)$ & 0.001 & & \\
\hline $\mathrm{WC}(\mathrm{cm})$ & $-0.07(-0.10,-0.03)$ & $<0.001$ & $-0.05(-0.08,-0.02)$ & 0.005 \\
\hline $\mathrm{HC}(\mathrm{cm})$ & $-0.06(-0.10,-0.02)$ & 0.006 & & \\
\hline Fat mass $(\mathrm{kg})$ & $-0.06(-0.10,-0.02)$ & 0.007 & & \\
\hline Muscle mass (kg) & $-0.16(-0.26,-0.06)$ & 0.003 & & \\
\hline Visceral fat rating & $-0.24(-0.37,-0.10)$ & 0.001 & & \\
\hline $\mathrm{TC}(\mathrm{mmol} / \mathrm{l})$ & $0.22(-0.22,0.65)$ & 0.324 & & \\
\hline HDL cholesterol $(\mathrm{mmol} / \mathrm{l})$ & $2.60(1.24,3.97)$ & $<0.001$ & $1.83(0.47,3.20)$ & 0.010 \\
\hline LDL cholesterol $(\mathrm{mmol} / \mathrm{l})$ & $0.16(-0.35,0.66)$ & 0.541 & & \\
\hline $\mathrm{TG}(\mathrm{mmol} / \mathrm{l})$ & $-0.30(-0.67,0.07)$ & 0.108 & & \\
\hline Glucose $(\mathrm{mmol} / \mathrm{l})$ & $0.02(-0.15,0.19)$ & 0.800 & & \\
\hline hs-CRP (mg/ml) & $-0.07(-0.14,0.01)$ & 0.088 & & \\
\hline $\operatorname{Insulin}(\mu \mathrm{U} / \mathrm{ml})$ & $-0.038(-0.080,-0.004)$ & 0.074 & & \\
\hline Energy (kcal/day) & $-0.001(-0.002,0.001)$ & 0.272 & & \\
\hline Protein (g/day) & $-0.007(-0.036 .0 .021)$ & 0.608 & & \\
\hline Carbohydrate (g/day) & $-0.006(-0.016,0.003)$ & 0.193 & & \\
\hline Fat (g/day) & $-0.015(-0.054,0.024)$ & 0.433 & & \\
\hline Saturated fat (g/day) & $0.032(-0.122,0.185)$ & 0.678 & & \\
\hline MUFA (g/day) & $-0.052(-0.205,0.102)$ & 0.501 & & \\
\hline PUFA (g/day) & $-0.107(-0.251,0.037)$ & 0.140 & & \\
\hline Calcium (mg/day) & $0.000(-0.002,0.003)$ & 0.928 & & \\
\hline Phosphorus (mg/day) & $-0.001(-0.002,0.001)$ & 0.274 & & \\
\hline Iron (mg/day) & $-0.070(-0.155,0.015)$ & 0.105 & & \\
\hline Cholesterol (mg/day) & $-0.004(-0.012,0.003)$ & 0.228 & & \\
\hline Thiamin (mg/day) & $0.020(-2.251,2.291)$ & 0.986 & & \\
\hline Riboflavin (mg/day) & $0.225(-0.992,1.442)$ & 0.711 & & \\
\hline Niacin (mg NE/day) & $-0.062(-0.264,0.139)$ & 0.536 & & \\
\hline Folate $(\mu \mathrm{g} /$ day $)$ & $-0.002(-0.013,0.009)$ & 0.695 & & \\
\hline Vitamin C (mg/day) & $0.002(-0.003,0.007)$ & 0.511 & & \\
\hline Vitamin E (mg/day) & $-0.047(-0.237,0.144)$ & 0.624 & & \\
\hline Selenium ( $\mu \mathrm{g} /$ day $)$ & $-0.010(-0.042,0.021)$ & 0.517 & & \\
\hline Fiber (g/day) & $-0.087(-0.369,0.194)$ & 0.534 & & \\
\hline Sugar (g/day) & $0.003(-0.025,0.030)$ & 0.857 & & \\
\hline
\end{tabular}

Note. $\mathrm{BMI}=$ body mass index, $\mathrm{WC}=$ Waist circumference; $\mathrm{HC}=$ hip circumference; $\mathrm{TC}=$ total Cholesterol; $\mathrm{HDL}=$ high density lipoprotein cholesterol; $\mathrm{LDL}=$ low density lipoprotein cholesterol; $\mathrm{TG}=$ triglyceride; hs-CRP=high sensitivity $\mathrm{C}$ reactive protein; MUFA=monounsaturated fatty acid; PUFA=polyunsaturated fatty acid

${ }^{\mathrm{a} C}$ Crude regression coefficient

bAdjusted regression coefficient

Stepwise multiple linear regression method applied. Model assumptions were fulfilled.

Interactions amongst independent variables and multicollinearity were not applicable.

Coefficient of determination $\left(\mathrm{R}^{2}\right)=0.377$

with BMI levels ${ }^{26}$ indicating that obese individuals commonly have lower adiponectin levels based on their abdominal adiposity. On the contrary, higher levels of adiponectin were resorted in some obese individuals with higher subcutaneous adipose tissueto-visceral adipose tissue ratios where the ratios were significantly associated with adiponectin. ${ }^{27}$ 
Table 3 Associations of nutritional status with HMW adiponectin among healthy controls

\begin{tabular}{|c|c|c|c|c|}
\hline \multirow[t]{2}{*}{ Variables } & \multicolumn{2}{|l|}{ Simple linear regression } & \multicolumn{2}{|c|}{ Multiple linear regression } \\
\hline & $\mathrm{b}^{\mathrm{a}}(95 \% \mathrm{CI})$ & $\mathrm{p}$ value & $\begin{array}{l}\text { Adjusted b }^{\mathrm{b}} \\
(95 \% \mathrm{CI})\end{array}$ & $\mathrm{p}$ value \\
\hline Weight,kg & $-0.08(-0.13,-0.03)$ & 0.001 & & \\
\hline Height,cm & $-0.09(-0.01,-0.19)$ & 0.083 & & \\
\hline BMI,kg/m² & $-0.20(-0.32,-0.08)$ & 0.001 & $-0.20(-0.32,-0.08)$ & 0.001 \\
\hline $\mathrm{WC}, \mathrm{cm}$ & $-0.08(-0.13,-0.03)$ & 0.001 & & \\
\hline $\mathrm{HC}, \mathrm{cm}$ & $-0.07(-0.13,-0,01)$ & 0.018 & & \\
\hline Fat mass,kg & $-0.11(-0.19,-0.04)$ & 0.002 & & \\
\hline Muscle mass,kg & $-0.08(-0.26,0.10)$ & 0.405 & & \\
\hline Visceral fat rating & $-0.15(-0.29,-0.01)$ & 0.035 & & \\
\hline $\mathrm{TC}(\mathrm{mmol} / \mathrm{l})$ & $-0.22(-0.78,0.33)$ & 0.420 & & \\
\hline HDL cholesterol (mmol/l) & $2.18(0.26,4.09)$ & 0.027 & & \\
\hline LDL cholesterol (mmol/l) & $-0.30(-0.92,0.32)$ & 0.339 & & \\
\hline TG $(\mathrm{mmol} / \mathrm{l})$ & $-1.05(-2.03,-0.08)$ & 0.035 & & \\
\hline Glucose (mmol/l) & $-0.10(-0.44,0.25)$ & 0.565 & & \\
\hline $\mathrm{hs}-\mathrm{CRP}^{\mathrm{a}}(\mathrm{mg} / \mathrm{ml})$ & $-0.04(-0.08,0.01)$ & 0.110 & & \\
\hline $\operatorname{Insulin}^{\mathrm{a}}(\mu \mathrm{U} / \mathrm{ml})$ & $-0.02(-0.07,0.03)$ & 0.459 & & \\
\hline Energy (kcal/day) & $-0.001(-0.003,0.002)$ & 0.545 & & \\
\hline Protein (g/day) & $-0.017(-0.060,0.027)$ & 0.452 & & \\
\hline Carbohydrate (g/day) & $-0.007(-0.020,0.005)$ & 0.255 & & \\
\hline Fat (g/day) & $-0.011(-0.061,0.039)$ & 0.665 & & \\
\hline Saturated fat (g/day) & $0.008(-0.184,0.199)$ & 0.937 & & \\
\hline MUFA (g/day) & $-0.032(-0.163,0.100)$ & 0.632 & & \\
\hline PUFA (g/day) & $-0.051(-0.208,0.106)$ & 0.518 & & \\
\hline Calcium (mg/day) & $0.001(-0.003,0.005)$ & 0.606 & & \\
\hline Phosphorus (mg/day) & $-0.001(-0.003,0.001)$ & 0.446 & & \\
\hline Iron (mg/day) & $-0.003(-0.105,0.098)$ & 0.946 & & \\
\hline Cholesterol (mg/day) & $-0.001(-0.012,0.010)$ & 0.858 & & \\
\hline Thiamin (mg/day) & $0.986(-1.680,3.651)$ & 0.462 & & \\
\hline Riboflavin (mg/day) & $2.114(0.144,4.083)$ & 0.036 & & \\
\hline Niacin (mg NE/day) & $0.009(-0.150,0.168)$ & 0.913 & & \\
\hline Folate $(\mu \mathrm{g} /$ day $)$ & $0.001(-0.013,0.015)$ & 0.887 & & \\
\hline Vitamin A ( $\mu \mathrm{g} /$ day $)$ & $0.001(-0.001,0.003)$ & 0.441 & & \\
\hline Vitamin C (mg/day) & $0.006(-0.006,0.018)$ & 0.341 & & \\
\hline Vitamin E (mg/day) & $-0.007(-0.362,0.347)$ & 0.968 & & \\
\hline Selenium ( $\mu \mathrm{g} /$ day) & $-0.018(-0.066,0.031)$ & 0.466 & & \\
\hline Dietary fiber (g/day) & $0.013(-0.386,0.411)$ & 0.949 & & \\
\hline Sugar (g/day) & $0.033(-0.005,0.070)$ & 0.084 & & \\
\hline
\end{tabular}

Note. $\mathrm{BMI}=$ body mass index, $\mathrm{WC}=$ Waist circumference; $\mathrm{HC}=$ hip circumference; $\mathrm{TC}=$ total Cholesterol; $\mathrm{HDL}=$ high density lipoprotein cholesterol; LDL=low density lipoprotein cholesterol; $\mathrm{TG}=$ triglyceride; hs-CRP=high sensitivity $\mathrm{C}$ reactive protein; MUFA=monounsaturated fatty acid; PUFA=polyunsaturated fatty acid

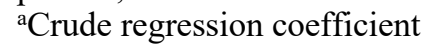

${ }^{\mathrm{b}}$ Adjusted regression coefficient

Stepwise multiple linear regression method applied. Model assumptions were fulfilled.

Interactions amongst independent variables and multicollinearity were not applicable.

Coefficient of determination $\left(\mathrm{R}^{2}\right)=0.168$

Obesity is recognized as risk factor for breast cancer among both post- and pre-menopausal women. ${ }^{28}$ Excess adipose tissue significantly increases the risk of breast cancer by $30-50 \% .{ }^{29}$ Understanding the role of obesity in carcinogenesis is of major importance, especially for obese women with breast 
cancer. Recently, it has been proposed that the association between cancer development and adiposity is related to (1) sex hormone metabolism, (2) insulin and insulin-like growth factor (IGF) signaling and (3) the physiology and pathological processes of adipokines. ${ }^{30}$

Our study also indicated that BMI was negatively associated with HMW adiponectin level among healthy controls. Similarly, Nakanishi and colleagues (2016) also who concluded that BMI was significantly lower in increased adiponectin among healthy men. ${ }^{31}$ In contrast, a cohort study among healthy males and females showed no significant association in women between BMI and adiponectin but interestingly, positive association of BMI with adiponectin in males possibly is due to significantly higher levels of adiponectin levels in men as compared to that in women. ${ }^{32}$ Decreased plasma testosterone in obese male ${ }^{33}$ may also explain the higher levels of adiponectin in man since testosterone has been reported to selectively decrease circulating levels of HMW adiponectin by inhibiting its secretion from the adipocytes. ${ }^{34}$

A similar outcome was also be reported in a disease-related group where negative correlation between BMI and adiponectin has been established among breast cancer patients. ${ }^{35}$ Moreover, patients with chronic obstructive pulmonary disease had remarkably higher adiponectin levels which are inversely correlated with BMI. ${ }^{36}$ The elevation in adiponectin level may be associated with body weight loss among these patients. ${ }^{37}$ In fact, adiponectin levels was inversely correlated with BMI and was downregulated with obesity. ${ }^{38}$ This is supported by a dietary and exercise intervention study which indicated that weight loss was inversely associated with adiponectin concentrations. ${ }^{39}$ However, BMI and adiponectin were positively correlated in patients with multiple sclerosis though the correlation was not significant. ${ }^{40}$

This study demonstrated that HDL cholesterol was significantly associated with HMW adiponectin. The current result support the previous study showing significant positive correlation between adiponectin levels and HDL cholesterol. ${ }^{41}$ HDL cholesterol had been proposed to have cardioprotective effect ${ }^{42}$ and it is possible that the form of HMW adiponectin may carry a lipid-soluble factor. ${ }^{43}$ According to Rothenbacher (2005), high serum concentration may acted as protective effect when mediated by the effects of lipoprotein

metabolism remarkably HDL cholesterol. This was concluded based on a study among patients with coronary heart disease presented strong correlation between adiponectin and HDL cholesterol. ${ }^{44}$ However, no significant direct effect of HDL cholesterol on adiponectin among type 2 diabetes cases except this relationship was intervened with pre-heparin lipoprotein lipase, a major enzyme in lipoprotein metabolism. ${ }^{45}$

Recent epidemiological study have shown a strong relationship between breast cancer and lipid disorders, including HDL cholesterol. ${ }^{46}$ Declined HDL cholesterol contributed to elevated breast cancer risk. ${ }^{47} \mathrm{~A}$ case-control study conducted to determine the correlation of adiponectin with risk factors of breast cancer among premenopause and post menopause women found that HDL cholesterol levels were significantly lower in controls than cases as well as positive correlation between adiponectin and HDL cholesterol. ${ }^{48}$

In conclusion, this study suggests that there is an association between nutritional status and HMW adiponectin. WC, BMI and HDL cholesterol had significant relationship with HMW adiponectin. Breast cancer in Malaysia could be prevented through nutritional education via public health programs.

\section{Conflict of Interest}

The authors of this paper declare there is no conflict of interest regarding this research.

\section{Open Access}

This article is distributed under the terms of the Creative Commons Attribution 4.0 International Licence(http://creativecommons.org/licenses/by/4.0 ), which permits unrestricted use, distribution, and reproduction in any medium, provided you give appropriate credit to the original author(s) and the source, provide a link to the Creative Commons license, and indicate if changes were made.

\section{Acknowledgement}


This study was financially funded by Universiti Sains Malaysia RUT grant (1001/PPSP/853005).

\section{References}

1. Forouzanfar $\mathrm{MH}$, Foreman $\mathrm{KJ}$, Delossantos AM, Lozano R, Lopez AD, Murray CJ, et al. Breast and cervical cancer in 187 countries between 1980 and 2010: a systematic analysis. The lancet 2011 Oct;378(9801):1461-84. [Google Scholar]

2. Basen-Engquist K, Chang M. Obesity and cancer risk: recent review and evidence. Current oncology reports 2011 Feb;13(1):716. [Google Scholar]

3. Institute for Public Health. (2015). National of Health and Morbidity Survey 2015 Volumn II Non-Communicable Disease, Risk Factors \& Other Health Problems. Malaysia: Institute for Public Health, Ministry of Health

4. Shakersain B, Santoni G, Faxen-Irving G, Rizzuto D, Fratiglioni L, Xu W. Nutritional status and survival among old adults: an 11year population-based longitudinal study. European journal of clinical nutrition 2016;70(3):320. [Google Scholar]

5. Bechard LJ, Duggan C, Touger-Decker R, Parrott JS, Rothpletz-Puglia P, Byham-Gray $\mathrm{L}$, et al. Nutritional status based on body mass index is associated with morbidity and mortality in mechanically ventilated critically ill children in the PICU. Critical care medicine 2016;44(8):1530. [Google Scholar]

6. Jeejeebhoy KN, Detsky AS, Baker JP. Assessment of nutritional status. Journal of Parenteral and Enteral Nutrition 1990;14:193. [Google Scholar]

7. American Cancer Society. (2016). Cancer Prevention \& Early Detection, Facts \& Figures: 2015-2016. Retrieved from https://www.cancer.org/content/dam/cancer-

org/research/cancer-facts-and-

statistics/cancer-prevention-and-early-

detection-facts-and-figures/cancer-

prevention-and-early-detection-facts-and-

figures-2015-2016.pdf

8. Bail, J., Meneses, K., \& Demark-Wahnefried, W. (2016). Nutritional status and diet in cancer prevention. Paper presented at the Seminars in Oncology Nursing.
9. Sahran, N. F., Harith, S., \& Mohamed, R. (2016). Prevalence of geriatric malnutrition and its associated factors at the Hospital Universiti Sains Malaysia, Kelantan. Malaysian journal of nutrition, 22(1), 41-53.

10. Coelho M, Oliveira T, Fernandes R. State of the art paper Biochemistry of adipose tissue: an endocrine organ. Archives of Medical Science 2013 Mar;9(2):191-200. [Google Scholar]

11. Ronti T, Lupattelli G, Mannarino E. The endocrine function of adipose tissue: an update. Clinical endocrinology 2006;64(4):355-65. [Google Scholar]

12. Zhu N, Pankow JS, Ballantyne CM, Couper D, Hoogeveen RC, Pereira M, et al. Highmolecular-weight adiponectin and the risk of type 2 diabetes in the ARIC study. The Journal of Clinical Endocrinology \& Metabolism 2010 Nov;95(11):5097-104. [Google Scholar]

13. Waki H, Yamauchi T, Kamon J, Kita S, Ito Y, Hada Y, et al. Generation of globular fragment of adiponectin by leukocyte elastase secreted by monocytic cell line THP-1. Endocrinology 2005 Feb;146(2):790-6. [Google Scholar]

14. Arita Y, Kihara S, Ouchi N, Maeda K, Kuriyama H, Okamoto Y, et al. Adipocytederived plasma protein adiponectin acts as a platelet-derived growth factor-BB-binding protein and regulates growth factor-induced common postreceptor signal in vascular smooth muscle cell. Circulation 2002 Jun;105(24):2893-8. [Google Scholar]

15. Ye R, Scherer PE. Adiponectin, driver or passenger on the road to insulin sensitivity. Molecular metabolism 2013 Aug;2(3):133-41. [Google Scholar]

16. Katira A, Tan PH. Adiponectin and its receptor signaling: an anti-cancer therapeutic target and its implications for anti-tumor immunity. Expert opinion on therapeutic targets 2015 Aug;19(8):1105-25. [Google Scholar]

17. Shahar S, Salleh RM, Ghazali AR, Koon PB, Mohamud WN. Roles of adiposity, lifetime physical activity and serum adiponectin in occurrence of breast cancer among Malaysian women in Klang Valley. Asian Pac J Cancer Prev 2010 Jan;11(1):61. [Google Scholar]

18. Fuhrman BJ, Freedman DM, Bhatti P, Doody $\mathrm{MM}, \mathrm{Fu} \mathrm{YP}$, Chang SC, et al. Sunlight, 
polymorphisms of vitamin D-related genes and risk of breast cancer. Anticancer research 2013 Feb;33(2):543-51. [Google Scholar]

19. Trieu PD, Mello-Thoms C, Peat JK, Do TD, Brennan PC. Risk Factors of Female Breast Cancer in Vietnam: A Case-Control Study. Cancer research and treatment: Official journal of Korean Cancer Association 2017;49(4):990. [Google Scholar]

20. Norlaili AA, Fatihah MA, Daliana NF, Maznah D. Breast Cancer Awareness of Rural Women in Malaysia: is it the Same as in the Cities. Asian Pacific Journal of Cancer Prevention 2013;14(12):7161-4. [Google Scholar]

21. Yip $\mathrm{CH}$, Bhoo PN, Teo S. A review of breast cancer research in Malaysia. Med J Malaysia 2014;69(suppl A):8-22. [Google Scholar]

22. Abdullah A, Abdullah KL, Yip CH, Teo SH, Taib NA, Ng CJ. The decision-making journey of Malaysian women with early breast cancer: A qualitative study. Asian Pacific Journal of Cancer Prevention 2013;14(12):7143-7. [Google Scholar]

23. Boucher BA, Wanigaratne S, Harris SA, Cotterchio M. Postdiagnosis Isoflavone and Lignan Intake in Newly Diagnosed Breast Cancer Patients: Cross-Sectional Survey Shows Considerable Intake from Previously Unassessed High-Lignan Foods. Current Developments in Nutrition 2017 Dec;2(3). [Google Scholar]

24. Vetto JT, Luoh SW, Naik A. Breast cancer in premenopausal women. Current problems in surgery 2009 Dec;46(12):944-1004. [Google Scholar]

25. Strumylaite, L., Kregzdyte, R., Poskiene, L., Bogusevicius, A., Pranys, D., \& Norkute, R. (2017). Association between lifetime exposure to passive smoking and risk of breast cancer subtypes defined by hormone receptor status among non-smoking Caucasian women. PLoS ONE, 12(2), e0171198. doi:10.1371/journal.pone.0171198

26. Ahl S, Guenther M, Zhao S, James R, Marks J, Szabo A, et al. Adiponectin levels differentiate metabolically healthy vs unhealthy among obese and nonobese white individuals. The Journal of Clinical Endocrinology \& Metabolism 2015 Nov;100(11):4172-80. [Google Scholar]
27. Guenther M, James R, Marks J, Zhao S, Szabo A, Kidambi S. Adiposity distribution influences circulating adiponectin levels. Translational Research 2014 Oct;164(4):2707. [Google Scholar]

28. Amadou A, Ferrari P, Muwonge R, Moskal A, Biessy C, Romieu I, et al. Overweight, obesity and risk of premenopausal breast cancer according to ethnicity: a systematic review and dose-response meta-analysis. Obesity Reviews 2013;14(8):665-78. [Google Scholar]

29. Huang Z, Hankinson SE, Colditz GA, Stampfer MJ, Hunter DJ, Manson JE, et al. Dual effects of weight and weight gain on breast cancer risk. Jama 1997 Nov;278(17):1407-11. [Google Scholar]

30. Booth A, Magnuson A, Fouts J, Foster M. Adipose tissue, obesity and adipokines: role in cancer promotion. Hormone molecular biology and clinical investigation 2015 Jan;21(1):57-74. [Google Scholar]

31. Nakanishi $K$, Nishida $M$, Yamamoto $R$, Koseki M, Moriyama T, Yamauchi-Takihara $\mathrm{K}$. Association between N-terminal pro-brain natriuretic peptide and adiponectin in healthy Japanese men. Clinica Chimica Acta 2016 Sep;460:138-41. [Google Scholar]

32. Pointer, M. A., Bridges, L., Wells, C., Bolin, D., \& Greene, N. (2015). Abstract P240: Gender Differences in the Association of Adiponectin and BMI in a Rural Cohort of African Americans. Hypertension, 66(Suppl 1), AP240-AP240.

33. Botella-Carretero JI, Balsa JA, Gomez-Martin JM, Peromingo R, Huerta L, Carrasco M, et al. Circulating free testosterone in obese men after bariatric surgery increases in parallel with insulin sensitivity. Journal of endocrinological investigation 2013 Apr;36(4):227-32. [Google Scholar]

34. Xu A, Chan KW, Hoo RL, Wang Y, Tan KC, Zhang J, et al. Testosterone selectively reduces the high molecular weight form of adiponectin by inhibiting its secretion from adipocytes. Journal of Biological Chemistry 2005 May;280(18):18073-80. [Google Scholar]

35. Duggan C, Irwin ML, Xiao L, Henderson KD, Smith AW, Baumgartner RN, et al. Associations of insulin resistance and adiponectin with mortality in women with 
breast cancer. Journal of Clinical Oncology 2011 Jan;29(1):32. [Google Scholar]

36. Bianco A, Nigro E, Monaco ML, Matera MG, Scudiero O, Mazzarella G, et al. The burden of obesity in asthma and COPD: Role of adiponectin. Pulmonary pharmacology \& therapeutics 2017 Apr;43:20-5. [Google Scholar]

37. Tomoda K, Yoshikawa M, Itoh T, Tamaki S, Fukuoka A, Komeda K, et al. Elevated circulating plasma adiponectin in underweight patients with COPD. Chest 2007 Jul;132(1):135-40. [Google Scholar]

38. Wei EK, Giovannucci E, Fuchs CS, Willett WC, Mantzoros CS. Low plasma adiponectin levels and risk of colorectal cancer in men: a prospective study. Journal of the National Cancer Institute 2005 Nov;97(22):1688-94. [Google Scholar]

39. Abbenhardt C, McTiernan A, Alfano CM, Wener MH, Campbell KL, Duggan C, et al. Effects of individual and combined dietary weight loss and exercise interventions in postmenopausal women on adiponectin and leptin levels. Journal of internal medicine 2013;274(2):163-75. [Google Scholar]

40. Winsz-Szczotka K, Kuźnik-Trocha K, Komosińska-Vassev K, Kucharz E, Kotulska A, Olczyk K. Relationship between adiponectin, leptin, IGF-1 and total lipid peroxides plasma concentrations in patients with systemic sclerosis: possible role in disease development. International journal of rheumatic diseases 2016;19(7):706-14. [Google Scholar]

41. Falahi E, Rad AH, Roosta S. What is the best biomarker for metabolic syndrome diagnosis. Diabetes \& Metabolic Syndrome: Clinical Research \& Reviews 2015 Oct;9(4):366-72. [Google Scholar]

42. Wen, S.-Y., Tamilselvi, S., Shen, C.-Y., Day, C. H., Chun, L.-C., Cheng, L.-Y., Ou, H.-C., Chen, R.-J., Viswanadha, V. P., Kuo, W.-W. (2017). Protective effect of HDL on NADPH oxidase-derived super oxide anion mediates hypoxia-induced cardiomyocyte apoptosis. PLoS ONE, 12(6), e0179492.

43. Hao G, Li W, Guo R, Yang JG, Wang Y, Tian $\mathrm{Y}$, et al. Serum total adiponectin level and the risk of cardiovascular disease in general population: A meta-analysis of 17 prospective studies. Atherosclerosis 2013 May;228(1):2935. [Google Scholar]

44. Rothenbacher D, Brenner H, März W, Koenig W. Adiponectin, risk of coronary heart disease and correlations with cardiovascular risk markers. European Heart Journal 2005 Jun;26(16):1640-6. [Google Scholar]

45. Maser RE, Lenhard MJ, Pohlig RT, Balagopal PB. Pre-heparin lipoprotein lipase mass as a potential mediator in the association between adiponectin and HDL-cholesterol in type 2 diabetes. Journal of clinical \& translational endocrinology 2017 Mar;7:7-11. [Google Scholar]

46. Lu CW, Yh, Lo, Chen $\mathrm{CH}$, Lin CY, Tsai CH, Chen PJ, et al. VLDL and LDL, but not HDL, promote breast cancer cell proliferation, metastasis and angiogenesis. Cancer letters 2017 Mar;388:130-8. [Google Scholar]

47. Furberg AS, Veierød MB, Wilsgaard T, Bernstein L, Thune I. Serum high-density lipoprotein cholesterol, metabolic profile, and breast cancer risk. Journal of the National Cancer Institute 2004 Aug;96(15):1152-60. [Google Scholar]

48. Assiri A, Kamel HF, Hassanien MF. . Resistin, visfatin, adiponectin, and leptin: risk of breast cancer in pre-and postmenopausal saudi females and their possible diagnostic and predictive implications as novel biomarkers. Disease markers. 2015; 2015. [Google Scholar] 